\title{
Financial Management for Health-System Pharmacists
}

Wilson AL, editor. American Sciety of Health-System Pharmacists, Bethesda, Maryland, 2009. Softcover, 323 pages. ISBN 978-1-58528-163-3. US\$99.00 (US\$79.00 for ASHP members).

Financial Management for Health-System Pharmacists was developed to "provide context, knowledge and specific detailed recommendations for the financial management of a health system pharmacy". The book appears to be aimed primarily at pharmacists practising in the US health care system who have recently moved into a pharmacy management position or are contemplating a career in health-system pharmacy management.

The 17 chapters in this book provide a comprehensive overview of the finance-related issues with which a pharmacy manager needs to be familiar to effectively manage a pharmacy department. The first few chapters deal with a high-level understanding of financial management within the context of the US health care system. The following half dozen or so chapters drill down into areas such as the budget process in health care, forecasting expenditures, financial management of human resources, analysis of budget variance, and management of pharmaceutical contracts and the supply chain. There is also a chapter on pharmaceutical reimbursement that offers interesting information on the complex reimbursement models that US hospitals have to deal with to obtain payment for the pharmaceutical services that they provide.

In the final section of the book, each chapter has a financial component, but these chapters seem to be written with a broader focus on pharmacy management in mind. The chapter entitled "Strategic Financial Planning" could easily have had the title 
"Strategic Planning", since it addresses a broad range of issues that must be considered as part of the planning process. Other chapters deal with benchmarking and productivity analysis, the factors that should be considered when an organization is considering outsourcing some or all pharmacy services, and a range of issues related to pharmacy education and research.

The contextual framework for this book is the US health care system, and for those who practise within that system it will undoubtedly be very useful. For Canadian pharmacy practitioners, the book's value is less clear. A Canadian pharmacist with a limited understanding of financial management in the Canadian health care system would have difficulty separating out the parts of this book that are relevant to the Canadian context. Conversely, a reader who already has a fairly in-depth understanding of how financial management works in the Canadian health care setting probably would not benefit very much from reading a book like this one. Financial Management for HealthSystem Pharmacists provides interesting insights into the financial management issues faced by our colleagues in the United States, but unless you are contemplating a move south of the border, it isn't a text that many Canadian hospital pharmacists will find particularly useful.

Kevin W Hall, BScPharm, PharmD

Winnipeg Regional Health Authority

Winnipeg, Manitoba 